\title{
Impaired Learning and Motor Behavior in Heterozygous Pafah1b1 (Lis1) Mutant Mice
}

\author{
Richard Paylor, ${ }^{1,2,7}$ Shinji Hirotsune, ${ }^{3,5}$ Michael J. Gambello, ${ }^{3}$ \\ Lisa Yuva-Paylor, ${ }^{1}$ Jacqueline N. Crawley, ${ }^{4}$ and Anthony Wynshaw-Boris ${ }^{3,6}$ \\ ${ }^{1}$ Department of Molecular and Human Genetics \\ ${ }^{2}$ Division of Neuroscience \\ Baylor College of Medicine \\ Houston, Texas 77030 USA \\ ${ }^{3}$ Genetic Disease Research Branch \\ National Human Genome Research Institute \\ National Institutes of Health \\ Bethesda, Maryland 20892 USA \\ ${ }^{4}$ Section on Behavioral Neuropharmacology \\ Experimental Therapeutics Branch \\ National Institute of Mental Health \\ Bethesda, Maryland 20892 USA
}

\begin{abstract}
Heterozygous mutation or deletion of Pafab1b1 (LIS1) in humans is associated with syndromes with type 1 lissencephaly, a severe brain developmental disorder resulting from abnormal neuronal migration. We have created Lis1 heterozygous mutant mice by gene targeting. Heterozygous mutant mice are viable and fertile, but display global organizational brain defects as a result of impaired neuronal migration. To assess the functional impact of the mutation, Lis 1 heterozygous mice and their wild-type littermates were evaluated on a wide variety of behavioral tests. Lis1 mutant mice displayed abnormal hindpaw clutching responses and were impaired on a rotarod test. Lis1 heterozygous mice were also impaired in the spatial learning version of the Morris water task. Impaired motor
\end{abstract}

Present Maryland addresses: ${ }^{5}$ The Institute for Animal Genetics, Odakura, Nishigo, Nishi-Shirakawa, Fukushima 961, Japan; 'Departments of Pediatrics and Medicine, University of California at San Diego (UCSD) School of Medicine, La Jolla, California 92093-0627 USA.

${ }^{7}$ Corresponding author. behavior and spatial learning and memory in Lis1 mutant mice indicates that impaired neuronal migration can have functional effects on complex behavioral responses. The behavioral findings also support the use of the Lis1 mutant mice as a model from human type 1 lissencephaly.

\section{Introduction}

During brain development, progenitor neurons arising in the developing neural tube migrate to their eventual adult location, sending out axonal and dendritic processes to synapse with correct targets. The characterization of mutants resulting from genetic abnormalities of neuronal migration has provided insight into the molecular genetic pathways guiding this process. For example, humans with hemizygous deletions of $17 \mathrm{p} 13.3$ have isolated lissencephaly sequence (ILS) or MillerDieker syndrome (MDS). These disorders are characterized by type I or classic lissencephaly (agyria/ pachygyria), a human brain developmental disorder manifested by smooth brain surfaces and disorganized cortical layering that is thought to result from abnormal neuronal migration (Dobyns et al. 1993). ILS and MDS patients have profound mental retardation with other neurologic disturbances, including seizures. The cerebral hemi-

LEARNING \& MEMORY 6:521-537 @ 1999 by Cold Spring Harbor Laboratory Press ISSN1072-0502/99 \$5.00

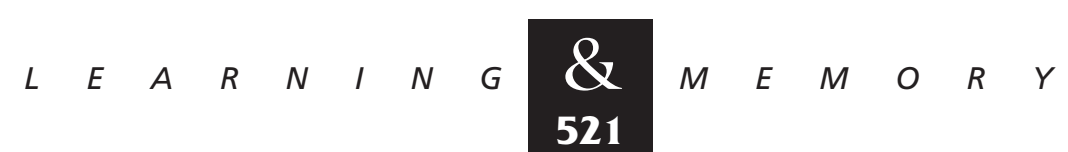


spheres of these patients display an overall thin cortical mantle with a thickened cortex consisting of four abnormal cell layers, enlarged lateral ventricles, and reduced white matter with occasional heterotopic neurons.

Using patient samples the gene responsible for type 1 lissencephaly in ILS and MDS, LIS1 was identified (Reiner et al. 1993). LIS1 is a regulatory subunit of platelet-activating factor acetylhydrolase (PAFAH) isoform $1 \beta$ (Hattori 1994). The developmental expression pattern of murine Lis 1 is consistent with an important role for this gene in early embryonic development and neuronal migration (Reiner et al. 1995; Albrecht et al. 1996). Lis1 is expressed in all three germ layers and extraembryonic tissue, and in the neuroepithelium of all regions of the central nervous system. During neurogenesis and postnatal central nervous system development, Lis1 is expressed in neurons undergoing migration, such as the ventricular zone, cortical plate, and developing cerebral cortex, the developing and mature hippocampus, the olfactory bulb, and the cerebellum. In addition, the other subunits of PAFAH, $\alpha 1$ and $\alpha 2$, are coexpressed with Lis 1 in neuronal tissue in a pattern consistent with the phenotype of ILS and MDS (Albrecht et al. 1996). These findings suggest that LIS1, and by implication PAFAH and PAF, play an important role in neuronal migration. However, the mechanism by which Lis 1 participates in neuronal migration is unknown.

To further understand the function of Lis 1, and to gain insight into the molecular genetic pathways responsible for neuronal migration, we have disrupted Lis1 in the mouse to examine the consequences of Lis1 deficiency. Lis 1 heterozygous mutant mice have disorganized cortical and hippocampal brain regions resulting from neuronal migration defects (Hirotsune et al. 1998). Homozygous mutants died soon after implantation, demonstrating an essential role for Lis 1 in early embryonic development. The present study was designed to examine the functional impact of the neuronal migration defects observed in Lis 1 heterozygous mutant mice.

During the past several years we have been successful at identifying roles for different genes in behavioral responses by evaluating mutant and control mice on a behavioral test battery (e.g., Crawley and Paylor 1997; Lijam et al. 1997; Sterneck et al. 1998). This behavioral test battery approach has also been an important tool to test specific hypotheses about the role of particular gene products in central nervous system function (e.g., Paylor et al. 1998). To determine whether the neuronal migration defects associated with Lis 1 deficiency has a functional impact on behavioral responses, wild-type and Lis 1 heterozygous mutant mice were evaluated on a behavioral test battery. The test battery includes several assays to assess different behavioral responses. A neurological screen is used to assess simple sensory/motor reflexes and simple motor skill. An open-field test is used to assess locomotor activity and anxiety-related behaviors. The light-dark box is used to assess anxiety-related responses more directly. The accelerating rotarod test is used to assess motor coordination and skill learning. Prepulse inhibition of the acoustic startle response is used to assess sensorimotor gating. Habituation of the acoustic startle response is used to assess simple nonassociative plasticity of a sensorimotor response. The hidden platform version of the Morris task was used to assess hippocampal-dependent spatial learning, whereas the visible platform task was used to assess nonhippocampal-dependent cued learning. Finally the hot-plate test was used to assess analgesiarelated responses. These tasks have been chosen because they assess different domains of central nervous system function. In addition, the hippocampus has been shown to play a role in exploration, sensorimotor gating, and spatial learning (e.g., Morris et al. 1982; Sutherland et al. 1982; Caine et al. 1992; Miller and Freedman 1995; Swerdlow et al. 1995; Stevens and Wear 1997). We have found that Lis 1 mutant mice have impaired motor behavior and spatial learning, but show normal exploratory activity, acoustic startle, and sensorimotor gating. These findings demonstrate a functional impact of neuronal migration defects in complex behaviors and support the use of Lis 1 mutant mice as a model for human type 1 lissencephaly.

\section{Experiment 1: Initial Characterization}

\section{Materials and Methods}

\section{ANIMALS}

Sixteen (10 female and 6 male) wild-type and 14 (11 female and 3 male) Pafab1b1 heterozygous (Lis1HET) mice were used for the behavioral experiments. Mice were generated as previously described (Hirotsune et al. 1998). Lis1HET mice had a single Lis 1 mutant allele. No mutant mice have

$$
\begin{array}{lllllllllllllll} 
& E & A & R & N & I & N & G & \begin{array}{l}
\boldsymbol{Z} \\
\mathbf{5 2 2}
\end{array} & M & E & M & O & R & Y
\end{array}
$$


been produced when attempts have been made to place the mutation on an inbred genetic background; therefore, in this study mice were from a mixed genetic background $(129 \mathrm{SvEv} \times \mathrm{NIH}$ Black Swiss). Mice were from $\mathrm{F}_{2}$ to $\mathrm{F}_{3}$ generations. One to four wild-type and Lis1HET mice from five different litters were used. Because there were only three male Lis1HET mutant mice, gender was not considered as a separate factor in any of the statistical analyses.

All animal experiments were carried out under protocols approved by the NHGRI and National Institute of Mental Health (NIMH) Animal Care and Use Committees and followed the National Institutes of Health (NIH) guidelines, "Using Animals in Intramural Research." Behavioral testing was conducted by an experimenter that was blind to the genotypes of the mice.

\section{NEUROLOGICAL SCREEN}

A simple neurological screen for motor and sensory responses was used (Paylor et al. 1998). In this screen, several physical features of the mice are recorded including body weight and core temperature. The mouse is then observed for $1 \mathrm{~min}$ in a new cage. The righting reflex, postural adjustment reflexes, eye blink, and ear twitch reflexes were then evaluated. Finally, several simple motor responses were evaluated using a wire suspension test and a vertical pole test. A more detailed description of the neurological screen can be found in Paylor et al. (1998).

One-way analysis of variance (ANOVA) was used to analyze the wire suspension data. Nonparametric analyses were used to analyze the pole test data.

\section{LOCOMOTOR ACTIVITY IN AN OPEN FIELD}

One to 2 days later, locomotor activity was evaluated by testing mice in an open field arena. Each subject was placed in the center of a clear Plexiglas chamber $(40 \mathrm{~cm} \times 40 \mathrm{~cm} \times 30 \mathrm{~cm})$ under standard room light conditions. Activity in the open field is quantitated by a computer-operated Digiscan optical animal activity system [RXYZCM (8), Omnitech Electronics] containing eight photoreceptor beams. Horizontal activity (locomotor activity), vertical activity (rearing), total distance $(\mathrm{cm})$, and center distance $(\mathrm{cm})$ were recorded. The center distance was divided by the total distance to obtain a center distance to total distance ratio. The center distance to total distance ratio can be used as an indicator of an anxiety-related behavioral response. Data were collected in 2-min intervals over a 30-min test session.

Locomotor activity data were analyzed using two-way (genotype $\times$ blocks of 2 min) ANOVAs with repeated measures.

\section{ROTAROD}

Three days later, mice were placed on an accelerating rotarod (UGO-Basile, model 7650) and the time that a mouse maintained its balance on the rotating drum was recorded. There are two responses that a mouse will exhibit when it begins to loose its balance on the rod. First, on some of the trials mice fall to the base of the rotarod when they loose their balance. On other trials, however, some of the mice hold onto the rotarod as they begin to fall and "passively" ride completely around the rod. The mice that passively ride around the rod will either continue to walk when they reach the top of the rod, or they will ride around the rod a second time.

We have defined operationally those mice that never passively ride around the rotarod as activeperforming mice, and those that ride around the rod at least one time during training as passiveperforming mice. For the active mice, the latency to fall is recorded for each trial. For the passive mice, the latency to fall off the rotarod, or the latency to the first ride around is recorded. Passiveperforming mice are allowed to continue to walk on the rotarod after the first passive rotation. However, trials are terminated if mice passively rotate around the rod twice consecutively. Thus, although passive-performing mice may occasionally ride around on the rotating drug, the data that are used for the analysis represent the time spent walking on the rotating drug. Each mouse was given three trials with a 45-min intertrial interval.

A three-way ANOVA [genotype $\times$ performance type (active vs. passive) $\times$ trial] with repeated measures was used to analyze the rotarod data.

ACOUSTIC STARTLE AND PREPULSE INHIBITION OF THE ACOUSTIC STARTLE RESPONSE

One day later, acoustic startle and prepulse inhibition of the acoustic startle responses was measured using two SR-Lab Systems (San Diego Instruments, San Diego, CA) as previously described (Lijam et al. 1997; Paylor and Crawley 1997). A test

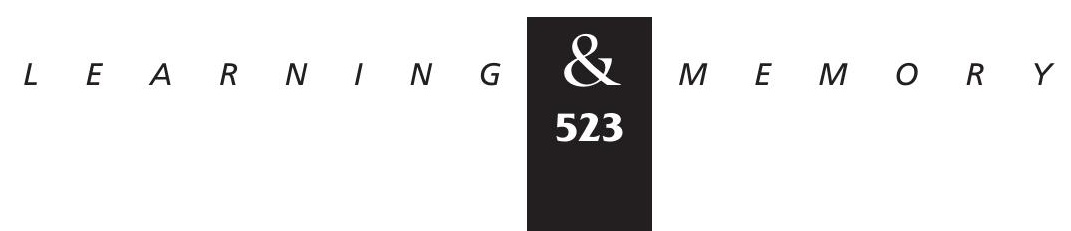


session began by placing a subject in the Plexiglas cylinder where it was left undisturbed for $5 \mathrm{~min}$. A test session consisted of seven trial types. One trial type was a $40-\mathrm{msec}, 120-\mathrm{dB}$ sound burst used as the startle stimulus. There were five different acoustic prepulse plus acoustic startle stimulus trials. The prepulse sound was presented $100 \mathrm{msec}$ before the startle stimulus. The 20 -msec prepulse sounds were $74,78,82,86$, or $90 \mathrm{~dB}$. Finally, there were trials where no stimulus was presented to measure baseline movement in the cylinders. Six blocks of the seven trial types were presented in pseudorandom order such that each trial type was presented once within a block of seven trials. The average intertrial interval was $15 \mathrm{sec}$ (ranged from 10 to 20 sec). The startle response was recorded for 65 msec (measuring the response every $1 \mathrm{msec}$ ) starting with the onset of the startle stimulus. The background noise level in each chamber was $70 \mathrm{~dB}$. The maximum startle amplitude recorded during the 65-msec sampling window was used as the dependent variable.

Percent prepulse inhibition of a startle response was calculated: $100-$ [(startle response on acoustic prepulse and startle stimulus trials/startle response alone trials) $\times 100]$.

Acoustic startle response data were analyzed using a Student's t-test. A two-way ANOVA (genotype $\times$ prepulse sound level) with repeated measures was used to analyze the percent prepulse inhibition data.

\section{SPATIAL LEARNING IN THE MORRIS WATER TASK}

Ten days later, mice were tested on the hidden platform version of the Morris (1981) water maze task as described previously (Upchurch and Wehner 1988; Paylor et al. 1998) in a circular polypropylene (Nalgene) pool $138 \mathrm{~cm}$ in diameter. The pool was located in a large room $(3.4 \mathrm{~m} \times 4.3 \mathrm{~m})$ with various extramaze visual cues. Each mouse was given 12 trials a day, in blocks of four trials for 3 consecutive days. During training, the time taken to locate the escape platform (escape latency) was recorded. After trial 24 and 36, each animal was given a 60 -sec probe trial. During the probe test, the platform was removed and quadrant search times and platform crossings were measured as described (Paylor et al. 1996). A Polytrack (San Diego Instruments) videotrack system was used to collect data during training and during the probe trials.

Two days after the last hidden platform training trial, mice were trained to locate a visible-cued platform. The visible cue was a gray plastic cube $(9$ $\mathrm{cm}$ ) attached to a pole such that it was $10 \mathrm{~cm}$ above the platform. On each trial of the visible platform test, the platform was randomly located in one of the four quadrants. Mice were given eight trials, in blocks of four trials, and the latency to find the platform was recorded for each trial.

For hidden platform training, the average escape latency data for a block of four trials were analyzed with two-way (genotype $\times$ trial block) ANOVA with repeated measures. Selective search data in probe trials were analyzed by individual one-way (Quadrants) repeated ANOVA and posthoc comparison tests. Swim speed for wild-type and Lis 1HET mutant mice were also determined on the two probe trials and analyzed using a one-way ANOVA. For visible platform training, the data for each individual trial was analyzed with a two-way (genotype $\times$ trial) Anova with repeated measures.

\section{HOT PLATE TEST}

Six weeks later, the hot plate test was used to evaluate the sensitivity to a painful stimulus. Mice were placed on a $55.0^{\circ} \mathrm{C}( \pm 0.3)$ hot plate and the latency to the first hind-paw response was recorded. The hind-paw response was either a foot shake or a paw lick.

Hot plate data were analyzed using a one-way ANOVA.

\section{Results}

\section{NEUROLOGIC SCREEN}

As previously reported (Hirotsune et al. 1998), and shown in Table 1, Lis1HET mutant mice tend to have lower body weight $[F(1,28)=4.207$, $P<0.05$ ], but normal body temperature $(P>0.05)$. The Lis1HET mutant mice also displayed a number of normal neurological responses and reflexes (Table 1). Both genotypes displayed similar responses on the vertical pole balance test and the wire hang suspension test $(P>0.05)$, which are simple measures of motor coordination and strength. However, during the wire suspension test $>40 \%$ of the Lis1HET mice displayed a hindlimb clutching response, whereby they held their hind-paws clutched to their body during the time that they were suspended from the wire. In addition, $\sim 30 \%$ of the mutants displayed a hind-limb clutching response during the tail suspension test. These behavioral differences (i.e., the presence of the hind-limb clutching response) on the wire

$$
\begin{array}{lllllllllllllll} 
& E & A & R & N & I & N & G & \mathbf{Q} & M & E & M & O & R & Y \\
\mathbf{5 2 4} & & & & & &
\end{array}
$$


Table 1: General motor and sensory responses of Lis1 heterozygous mutant and wild-type mice

\begin{tabular}{|c|c|c|}
\hline & Wild type & Lis1 mutant \\
\hline $\begin{array}{l}\text { Physical characteristics } \\
\text { weight } \\
\text { temperature } \\
\text { whiskers (\% with) } \\
\text { bald patches (\% with) } \\
\text { palpebral closure (\% with) } \\
\text { exophthalmos (\% with) } \\
\text { piloerection (\% with) }\end{array}$ & $\begin{array}{l}23.7( \pm 1.1) \\
38.5( \pm .1) \\
90 \\
0 \\
0 \\
0 \\
0\end{array}$ & $\begin{array}{l}20.7( \pm 0.73) \\
38.5( \pm .1) \\
90 \\
0 \\
0 \\
0 \\
0\end{array}$ \\
\hline $\begin{array}{l}\text { General behavioral observations } \\
\text { (\% subjects displaying response) } \\
\text { wild running } \\
\text { freezing } \\
\text { sniffing } \\
\text { licking } \\
\text { rearing } \\
\text { jumping } \\
\text { move around entire cage }\end{array}$ & $\begin{array}{r}0 \\
0 \\
100 \\
0 \\
100 \\
0 \\
100\end{array}$ & $\begin{array}{r}0 \\
0 \\
100 \\
0 \\
100 \\
0 \\
100\end{array}$ \\
\hline $\begin{array}{l}\text { Sensorimotor reflexes } \\
\text { (\% subjects displaying "normal response") } \\
\text { cage movement } \\
\text { righting } \\
\text { whisker response } \\
\text { eye blink } \\
\text { ear twitch }\end{array}$ & $\begin{array}{l}100 \\
100 \\
100 \\
100 \\
100\end{array}$ & $\begin{array}{l}100 \\
100 \\
100 \\
100 \\
100\end{array}$ \\
\hline $\begin{array}{l}\text { hot-plate test } \\
\text { [latency (sec) to first hind-paw response] }\end{array}$ & $5.1( \pm .5)$ & $4.8( \pm .6)$ \\
\hline $\begin{array}{l}\text { Motor responses } \\
\text { wire suspension time }(\mathrm{sec}) \\
\text { hind-paw clutching }(\%) \\
\text { pole test score } \\
\text { tail suspension (\% with normal response) }\end{array}$ & $\begin{array}{l}40.9( \pm 6) \\
0 \\
8.5( \pm 0.7) \\
100\end{array}$ & $\begin{array}{c}52( \pm 4.3) \\
43 * P<0.01 \\
6.4( \pm 1) \\
71 * P<0.05\end{array}$ \\
\hline $\begin{array}{l}\text { Elevated platform } \\
\text { latency to edge (sec) } \\
\text { no. exploratory nose pokes }\end{array}$ & $\begin{array}{l}1.7( \pm 0.4) \\
8.7( \pm 1.3)\end{array}$ & $\begin{array}{l}3.5( \pm 0.9) \\
7.9( \pm 1.1)\end{array}$ \\
\hline
\end{tabular}

Numbers represent the mean ( \pm S.E.M.). $\left(^{*}\right)$ Statistically significant difference (Fisher exact probability test) between Lis1 heterozygous mutant and wild-type mice.

and tail suspension tests were significant (Fisher's exact probability test, $P<0.05$ ) as no wildtype mouse displayed this abnormal response. Table 1 also shows that there was no difference $[F(1,27)=0.072, P=0.79]$ between mutant and wild-type mice in the latency to the first hind-paw response on the hot plate test.

\section{LOCOMOTOR ACTIVITY}

Locomotor activity in the open field was nor- mal in Lis1HET mice. The horizontal activity (Fig. 1A), vertical activity (Fig. 1B), and center distanceto-total distance ratio (Fig. 1C) were not statistically different between the two genotypes [horizontal activity, $F(1,28)=2.796, P=0.1057$; vertical activity, $F(1,28)=1.351, P=0.255$; center distance-to-total distance ratio, $F(1,28)=0.951$, $P=0.3378]$. Overall, horizontal activity decreased over the 30-min test session for both Lis1HET and wild-type mice $[F(14,392)=22.829, P=0.00001]$.

$$
\begin{array}{lllllllllllllll} 
& E & A & R & N & I & N & G & \mathbf{8} & M & E & M & 0 & R & Y
\end{array}
$$




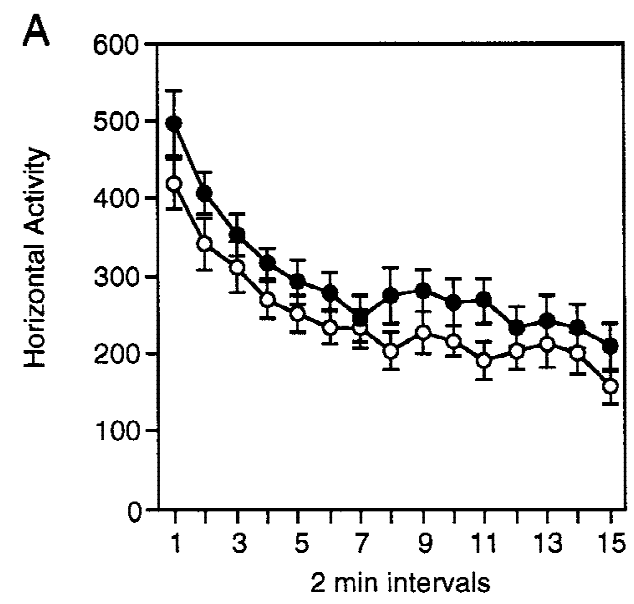

B

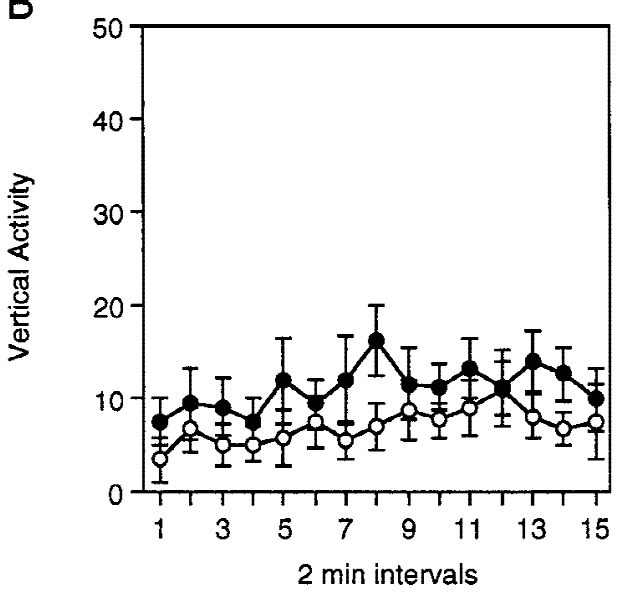

C

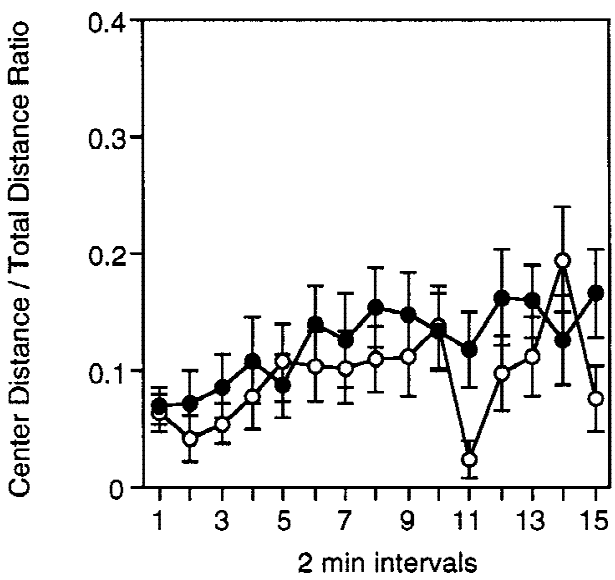

Figure 1: Horizontal activity $(A)$, vertical activity $(B)$, and the center distance-to-total distance ratio $(C)$ for $L$ is 1 heterozygous $(O,+/-)$ mutant and wild-type $(0,+/+)$ mice during the $30-\mathrm{min}$ open field test. There were no significant differences between $+/-$ and $+/+$ mice on any of the open field measurements $(P>0.1)$. Data are represented as the mean ( \pm S.E.M.)

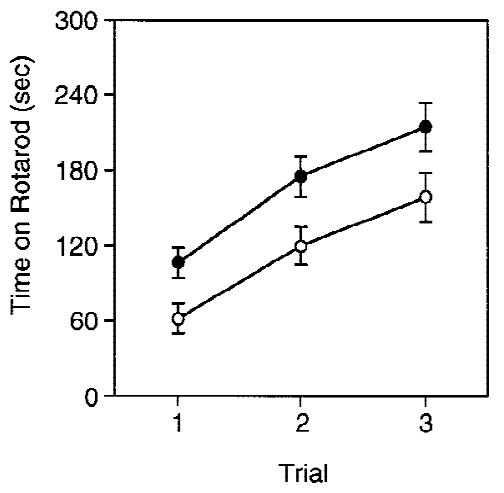

Figure 2: Time spent balanced on top of the rotating rod across three test trials for Lis 1 heterozygous $(O,+/-)$ mutant and wild-type $\left(\boldsymbol{O}_{+}+/+\right)$mice. Overall significant difference between Lis1 heterozygous (+/-) mutant and wild-type $(+/+)$ mice, $P<0.000001$. There were no significant differences $(P>0.5)$ between mice that used active- or passive-performing response strategies (see text). Data are represented as the mean ( \pm S.E.M.).

Exploration of the center of the open field also increased during testing for both Lis1HET and wild-type mice $[F(14,392)=3.289, P=0.0001]$. Vertical activity increased significantly for both Lis1HET and wild-type mice $[F(14,392)=1.8$, $P=0.0367]$. There were no significant interactions between genotype and time for the horizontal activity, vertical activity, or center distance-to-total distance ratio $[F<1.5, P>0.13]$.

\section{ROTAROD TEST}

The performance of Lis1HET and wild-type mice on the rotarod test is presented in Figure 2. The time that wild-type and Lis 1HET mice maintained their balance on the top of the rotating rod increased significantly over the three training trials $[F(2,52)=16.56, P=0.0000027]$. However, the time on the rotarod for Lis1HET mice was significantly less than that recorded for wild-type mice $[F(1,26)=7.302, P=0.012]$. There was no significant differences in the time on the rotarod between active-performing and passive-performing mice $[F(1,26)=0.413, P=0.525]$, and no interactions were significant $(P>0.15)$.

\section{ACOUSTIC STARTLE AND PREPULSE INHIBITION OF THE ACOUSTIC STARTLE RESPONSE}

Figure $3 \mathrm{~A}$ presents the acoustic startle response to the $120-\mathrm{dB}$ sound stimulus. The startle amplitude was similar between Lis1HET mutants

$$
\begin{array}{lllllllllllllll}
L & E & A & R & N & I & N & G & \underset{5}{\mathbf{5} 26} & M & E & M & O & R & Y
\end{array}
$$


and wild-type mice $[F(1,28)=1.045, P=0.3154]$. Figure $3 \mathrm{~B}$ displays the prepulse inhibition of the acoustic startle response data. In general, levels of prepulse inhibition increased across the prepulse sound levels $[F(4,112)=148.177, P=0.00001]$. There were no differences in the levels of prepulse inhibition of the acoustic startle response between Lis1HET and wild-type mice $[F(1,28)=0.118$, $P=0.7340]$. The genotype $\times$ prepulse sound level interaction was also not significant $[F(4,112)=1.984$, $P=0.1018]$.

\section{SPATIAL LEARNING IN THE MORRIS WATER TASK}

Figure 4 presents the time to find (escape latency) the hidden platform in the Morris water task for Lis1HET and wild-type mice. Overall, the es-

\section{A}

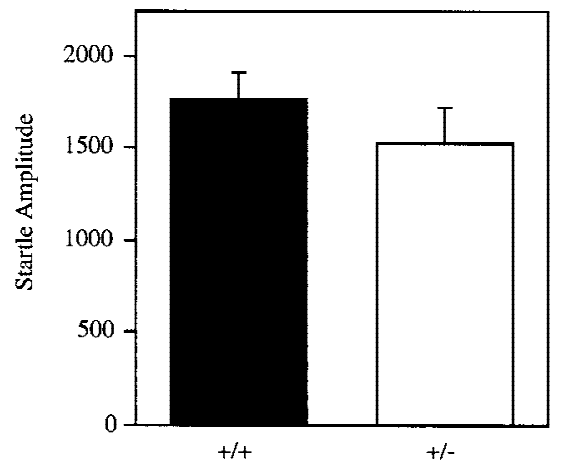

B

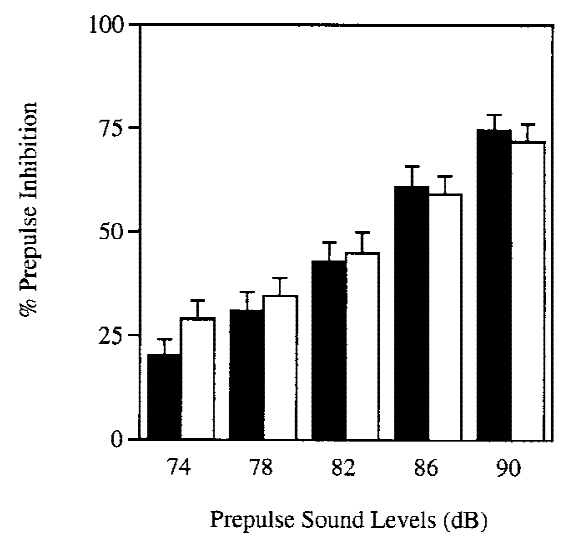

Figure 3: Startle amplitude to the $120-\mathrm{dB}$ stimulus $(A)$, and levels $(\%)$ of prepulse inhibition of the acoustic startle response $(B)$ for Lis1 heterozygous $(\square,+/-)$ mutant and wild-type $(\mathbf{\square},+/+)$ mice. There were no significant differences between $+/-$ and $+/+$ mice for the acoustic startle response $(P>0.3)$ or prepulse inhibition $(P>0.7)$. Data are represented as the mean ( \pm S.E.M.).

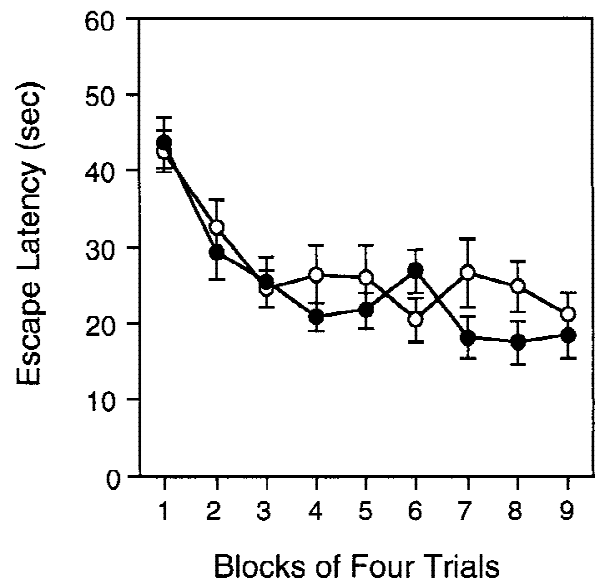

Figure 4: Latency to find the hidden platform in the Morris water task for Lis1 heterozygous $(O,+/-)$ mutant and wild-type $(\bullet,+/+)$ mice. There were no significant differences between $+/-$ and $+/+$ mice $(P>0.3)$. Data are represented as the mean ( \pm S.E.M.).

cape latencies decreased for both Lis1HET and wild-type mice during training $[F(8,224)=13.776$, $P=0.0001]$, and the difference in the escape latencies between Lis 1HET and wild-type mice was not significant $[F(1,28)=1.045, \quad P=0.3154]$. The genotype $\times$ trial block interaction was also not significant $[F(8,224)=1.483, P=0.1643]$.

Although the time to find the platform was not different between Lis1HET and wild-type mice, the probe data clearly indicate that the strategies used to find the platform were different. After the twenty-fourth (day 2) and thirty-sixth (day 3) trials, the platform was removed (probe trials) to determine whether mice were using a selective spatial search strategy to locate the hidden platform. During the day 2 probe trial (Fig. 5A, B) wild-type mice spent significantly more time in the training quadrant than the other three quadrants $[F(3,45)=14.546, P=0.0001 ;$ Newman-Keuls post hoc comparisons, trained $>$ all other quadrants, $P<0.0009]$, and they crossed the exact place where the platform had been located more often than equivalent sites in the other three quadrants $[F(3,45)=4.654, P=0.0065$; Newman-Keuls post hoc comparisons, trained $>$ all other quadrants, $P<0.02]$. Lis1HET mice, however, did not selectively search in the correct quadrant of the pool as assessed by the quadrant search data $[F(3,39)=0.955, P=0.4237]$, or platform crossing data $[F(3,39)=0.87, P=0.4649]$.

An additional 12 training trials appeared to improve the search pattern of Lis1HET mice

$$
\begin{array}{lllllllllllllll}
\hline & E & A & R & N & I & N & G & \underset{\mathbf{5 2 7}}{\boldsymbol{Z}} & M & E & M & O & R & Y
\end{array}
$$


Figure 5: Probe trial data after hidden platform training in the Morris water task for Lis1 heterozygous mutant and wild-type mice. Quadrant search time and number of platform crossings are presented for both the day $2(A, B)$ and day $3(C, D)$ probe trials. Data for the training quadrant is significantly higher than the data for each of the other three quadrants, $P<0.02$. Data for the training quadrant is significantly higher than the data for the quadrant to the right, $P<0.05$, but not significantly higher than the data for the other two quadrants, $P>0.05$. Data are represented as the mean ( \pm S.E.M.).

(Fig. 5C, D). However, they still did not selectively search in the correct quadrant of the pool during the day 3 probe trial. Lis1HET mice did not spend significantly more time in the correct quadrant of the pool compared to the other quadrants $[F(3,39)=2.505, P=0.0732]$. The platform crossing data did indicate that Lis1HET mice showed some selective search $[F(3,39)=3.466$, $P=0.0252]$, but the Newman-Keuls post hoc comparisons tests showed Lis 1 HET mice did cross the training site more often than the equivalent site in the quadrant to the right $(P<0.02)$, but not more often than the quadrant to the left or the opposite quadrant $(P>0.05)$. In contrast wild-type mice displayed selective search during the day 3 probe trial. Wild-type mice spent significantly more time in the training quadrant than the other three quadrants $[F(3,45)=12.564, \quad P=0.0001$; NewmanKeuls post hoc comparisons, trained $>$ all other quadrants, $P<0.0004$ ], and they crossed the exact place where the platform had been located more often than equivalent sites in the other three quadrants $[F(3,45)=17.762, P=0.0001$; NewmanKeuls post hoc comparisons, trained $>$ all other quadrants, $P<0.0002$ ]. It is important to point out that the total number of platform crossings was similar for wild-type and Lis1HET mutants indicating that the Lis1HETs were not simply thigmotaxic
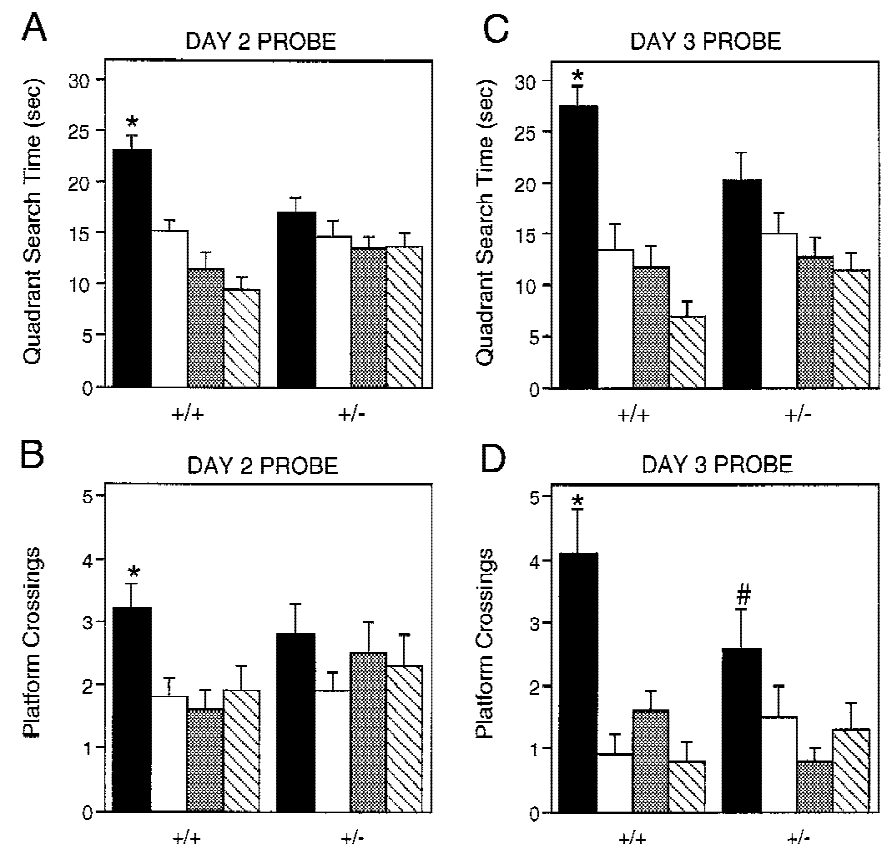

Quadrants
Trained $\square$ Left 圈 Right Opposite

and swimming along the pool wall. Finally, the swim speeds (data not shown) were not significantly different between wild-type and Lis1HET mice on the probe trials $(P>0.5)$ suggesting that the basic swimming skills of the mice were comparable.

The time to locate the visible platform (fig. 6) decreased across the eight trials for both Lis1HET and wild-type mice $[F(7,196)=7.712, P=0.0001]$, and the difference in the time to locate the platform was not different between mutant and wildtype mice $[F(1,28)=0.01, P>0.9]$.

\section{CORRELATIONAL ANALYSES}

The fact that the swim speed of Lis1HET mutant was not different from wild-type mice, and both genotypes performed similarly on the visible platform test, suggests that the motor impairments of the Lis1HET mutants was not affecting the swimming performance in the Morris task. To test further the hypothesis that poor spatial learning performance of Lis1HET mutants was associated with poor motor skills, we determined whether there were significant correlations between performance on the rotarod and spatial learning. The average time spent on the rotarod across the three trials was used in the analyses and correlated with

$$
\begin{array}{lllllllllllllll}
L & E & A & R & N & I & N & G & \begin{array}{c}
\boldsymbol{Q} \\
\mathbf{5 2 8}
\end{array} & M & E & M & O & R & Y
\end{array}
$$




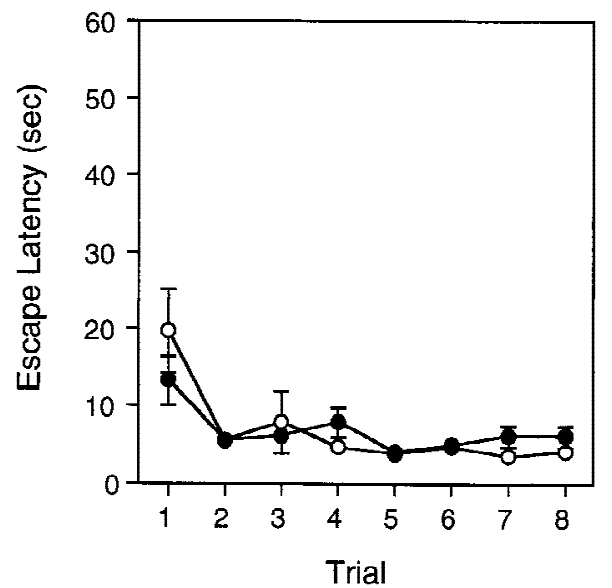

Figure 6: Latency to find the visible platform in the Morris water task for Lis1 heterozygous mutant and wild-type mice. There were no significant differences between $+/-(\bigcirc)$ and $+/+(\bigcirc)$ mice $(P>0.9)$. Data are represented as the mean ( \pm S.E.M.).

(1) the average quadrant search time for the training quadrant only across the two probes, (2) the average platform crossings for the training quadrant across the two probes, and (3) the average swim distance across the two probe trials. For these analyses the $P$ value that was accepted as statistically significant was reduced from $<0.05$ to $<0.017$, as the same rotarod data was used repeatedly to correlate with the three different probe values. Across both genotypes the performance on the rotarod was not significantly correlated $(P>0.017)$ with the average training site quadrant search time $(r=0.321)$, the average training site platform crossings $(r=0.393)$, or average swim distance $(r=0.7524)$. A separate analyses using only the data from the Lis1HET mice also produced no significant correlation between the rotarod performance and the average training site quadrant search time $(r=0.496)$, the average training site platform crossings $(r=0.245)$, or average swim distance $(r=0.341)$.

It is also interesting to note that there were no significant differences between the quadrant search time, platform crossing, or swim distance data between those Lis1HET mice that displayed an abnormal hind-limb clutching response during the neurological screen and the Lis1HET mutants that showed a normal response $(P<0.05)$.

The results from these types of analyses indicate that there is no significant relationship between poor motor skills and spatial learning in the Morris task.

\section{Experiment 2: Confirmation of Positive Phenotypes}

The primary objective of experiment 2 was to replicate and extend the positive findings from experiment 1 in a second, independent batch of mice. In experiment 1 we found that the time Lis1HET mutant mice maintained their balance on the rotarod was significantly less compared to wildtype controls. However, this test was limited to 1 day of training. It is possible that with further training, the Lis1HET mutant mice could have learned to stay on the rotarod as well as wild-type mice. In experiment 2, we trained Lis1HET mutant and wild-type mice on the rotarod over a 3-day test period.

In experiment 1, the time to locate the hidden platform during training on the Morris water task was not significantly different between wild-type and Lis1HET mutant mice. In addition, wild-type mice selectively searched in the correct quadrant of the pool where the platform had been located during the probe test trials. In contrast, most Lis1HET mutant mice did not selectively search in the correct quadrant of the pool during the probe trials. The fact that wild-type mice, but not Lis1HET mutant mice, selectively searched in the correct quadrant of the pool during the probe trial is consistent with the hypothesis that wild-type mice, but not Lis1HET mutant mice, learned to locate the hidden platform during training using a spatial search strategy. Experiment 2 was designed to test further this hypothesis using a random hidden platform test. In the random hidden platform test, mice are first trained to locate a hidden platform in a fixed location. Mice are given subsequently a series of trials in which the platform is either in the same training site, or in an equivalent site in one of the other three quadrants. If a mouse is learning to locate the hidden platform during training by using a selective spatial search strategy, then it will locate the platform when it is in its training site significantly faster than when it is in one of the other three sites. However, if a mouse is using a search strategy that is not spatially biased toward the area of the pool where the platform is located, but which takes them away from searching the wall, then the time to locate the platform during the random hidden platform test will be similar regardless of the platform location. Although the random hidden platform test is not routinely used, it has been used previously in studies examining spatial learning abilities of gene-targeted

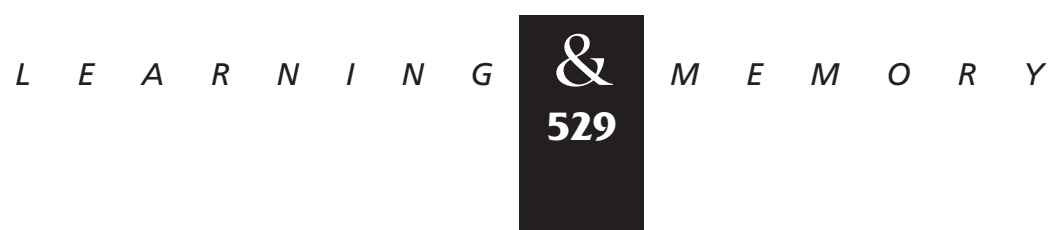


Paylor et al.

mutant mice (Silva et al. 1992; Abeliovich et al. 1993).

\section{Materials and Methods}

ANIMALS

Seventeen ( 9 female and 8 male) wild-type and 12 ( 4 female and 8 male) Lis 1 HET mice from at least seven different litters were used for the rotarod test in experiment 2 . Twelve ( 4 female and 7 male) of the wild-type and 11 of the mutant ( 3 female and 7 male) mice were also tested in the Morris water task. The mice were derived from seven different litters. Mice were shipped to Baylor College of Medicine (BCM) when they were $\sim 2$ to 3 months old. Behavioral testing began when the mice were $\sim 5$ months old. All experiments were carried out under protocols approved by the NHGRI and BCM's Animal Care and Use Committees and followed the NIH guidelines "Using Animals in Research." Behavioral testing was conducted by an experimenter that was blind to the genotypes of the mice.

\section{ROTAROD}

Mice were trained as described for experiment 1 except mice were given three trials a day for 3 consecutive days. Data are recorded as described in experiment 1, including identifying wild-type and Lis1HET mice as active-performers or passive-performers. A three-way ANOVA (genotype $\times$ performance type $\times$ trial) with repeated measures was used to analyze the rotarod data.

\section{RANDOM HIDDEN PLATFORM TEST FOR SPATIAL LEARNING}

Two months later, mice were tested on the hidden platform version of the Morris water maze task as previously described for experiment 1 . The same size pool was used in both experiment 1 and experiment 2; however, the testing room was different as experiment 1 was performed at NIH in Bethesda, and experiment 2 was performed at BCM.

Each mouse was given 12 trials a day, in blocks of four trials for 2 consecutive days. During training, the time taken to locate the escape platform (escape latency) was recorded. The random platform test was administered on day 3. During the random platform test, mice were given three trials with the platform in the original training location and three trials with the platform in the other three quadrants. Specifically, to ensure that mice were still swimming to the training site, the platform was located in the original training site on trials 1 and 2. On trials 3 to 6 the platform was either located in the training site, or it was located in the center of one of the other three quadrants.

The time to locate the platform was recorded for each trial. A two-way ANOVA (genotype $\times$ trial) with repeated measure was used to analyze the data from the 2 training days. For the random platform test, the average time to locate the platform when it was in the training site was compared to the average time to locate the platform when it was in one of the other three quadrants. A two-way ANOVA with repeated measures was used to analyze the random platform test data. In addition, a training site platform crossing value was determined for each subject by counting the number of times a subject crossed the training site when the platform was located in one of the other three quadrants. This training site platform crossing value was compared to the random site platform crossing value, which was generated by determining the average number of crossings in the other possible platform sites on trials when the platform was in the training site. Individual one-way ANOVAs were used to analyze the platform crossing data.

\section{Results}

\section{ROTAROD}

The results from the rotarod experiment are shown in Figure 7. There are several interesting features of these data. First, wild-type mice walked on top of the rotating rod significantly longer than the Lis1HET mice $[F(1,25)=22.325, P=0.000076]$. Second, mice categorized as passive performers were able to maintain their balance and walk on top of the rotarod significantly longer than those that are active performers $[F(1,25)=6.372$, $P=0.0183]$. In addition, there was a significant main effect of trials $[F(8,200)=34.384$, $P=0.0000001]$ indicating that the performance of mice improved with training. Third, the genotype $\times$ trial interaction was also significant $[F(8,200)=7.056, P=0.0000001]$. Simple effects analysis of the genotype $\times$ trial interaction indicated that wild-type spent significantly more time on the rotarod than Lis1HET mutants on all but the first trial (trial 1: $P=0.061$; trial 2-9: $P<0.0024$ ). Further analysis of the simple results also revealed

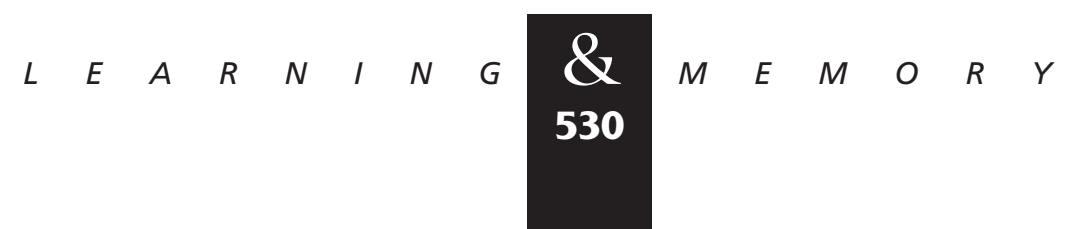




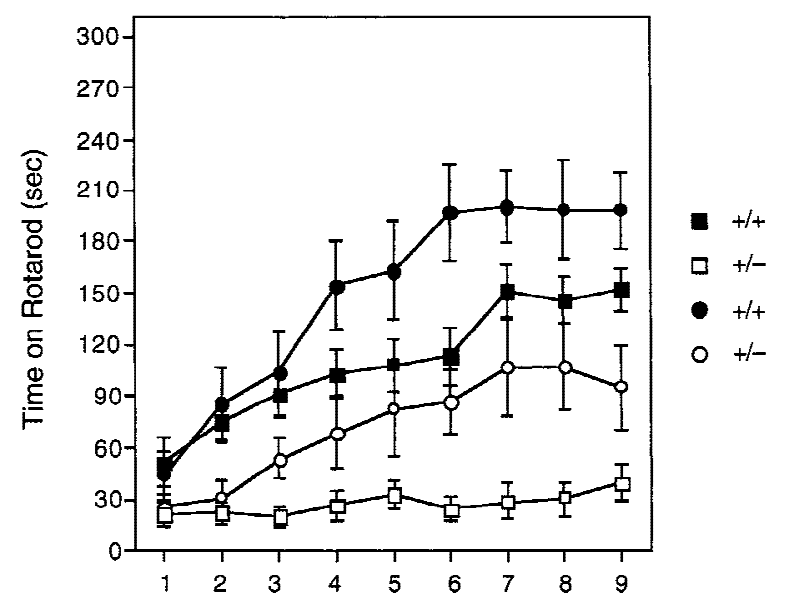

TRIAL

\author{
II Active \\ II Active \\ II Passive \\ II Passive
}

Figure 7: Time spent walking on top of the rotating rod across nine test trials for Lis1 heterozygous (+/-) mutant and wild-type $(+/+)$ mice that were characterized as using an active- or passive-performing strategy (see text for details). $+/+$ mice stayed walking on top of the rotarod significantly longer than $+/-$ mice $(P<0.00001)$. Mice characterized as passive-performing stayed on top of the rotarod significantly longer than active-performing mice $(P<0.02)$. Data are represented as the mean ( \pm S.E.M.).

that the asymptotic performance, as defined by no further significant improvement in performance, for Lis1HET and wild-type mice was reached at different points during training. There was no significant improvement $(P>0.05)$ in the Lis1HET mutants after trial 3. In contrast there was no further significant $(P>0.05)$ improvement in wild-type mice after trial 5 . Finally, the performance strategy $\times$ trial interaction was significant $[F(8,200)=5.832, P=0.000001]$. Follow-up analysis of this significant interaction revealed that mice using the passive strategy were able to walk significantly longer $(P<0.05)$ on the rotarod compared to the mice using the active strategy on trials 4-9, but not 1-3.

\section{RANDOM PLATFORM SPATIAL LEARNING TEST}

The data from one wild-type and one Lis1HET were not included in the analyses because their escape latency data were clearly outliers (i.e.,>2.5 standard deviations from the average).

Figure 8A shows the escape latency data for wild-type and Lis1HET mutant mice tested in the Morris water task for experiment 2. In contrast to the data from experiment 1, the Lis1HET mutant mice were significantly worse at locating the hidden platform compared to wild-type mice $[F(1,19)=9.532, P=0.006]$. The main effect of trials was also significant $[F(5,95)=17.39$, $P=0.000001]$, but the genotype $\times$ trial interaction was not significant $[F(5,95)=1.06, P=0.387]$. Consistent with experiment 1 , the swim speeds (data not shown) were not significantly different between wild-type and Lis1HET mutant mice across training $[F(1,19)=0.98, P=0.334]$.

During the random platform test, wild-type mice, but not Lis1HET mutants found the platform significantly faster when the platform was in the training site than when it was located in other sites (Fig. 8B). A two-way (genotype $\times$ platform site) ANOVA with repeated measures supports this observation. The main effect of genotype was not significant $[F(1,19)=0.10, P=0.754]$, however, the genotype $\times$ platform site interaction was statistically significant $[F(1,19)=4.487, \quad P=0.0475]$. Post hoc comparison of the interaction revealed that the time to locate the platform when it was in its training site was significantly shorter than when it was in one of the new sites for wild-type mice $(P=0.003)$. However, the time to locate the platform in the training site compared to other sites was not significantly different for Lis1HET mice $(P=0.267)$.

Analysis of the number of platform crossings (Fig. 8C) during the random platform test revealed that wild-type mice crossed the training site significantly more often when the platform was in the other sites compared to the number of times they crossed the other sites when the platform was in the training site $[F(1,10)=13.501, P=0.004]$. In contrast, Lis1HET mutants did not cross the training site significantly more often when the platform was in the other sites compared to the number of times they crossed the other sites when the platform was in the training site $[F(1,9)=0.662$, $P=0.437]$.

\section{Discussion}

Syndromes characterized by type I lissencephaly (agyria/pachygyria), such as ILS and MDS

$$
\begin{array}{lllllllllllllll}
L & E & A & R & N & I & N & G & \mathbf{8} & M & E & M & O & R & Y \\
\mathbf{5 3 1} & & & & & & &
\end{array}
$$


A

Figure 8: $(A)$ Latency to find the hidden platform during the training phase of the random platform test in the Morris water task for Lis 1 heterozygous $(O,+/-)$ mutant and wild-type $(\mathbf{0},+/+)$ mice. $\left(^{*}\right)$ Escape latencies are significantly different $(P)<0.007)$ between $+/+$ and $+/-$ mice. $(B)$ The average time to locate the platform during the random platform test trials. Data are the average escape latency for the three trials when the platform was in the trained site compared to the three trials when the platform was in the other sites. (C) The average number of platform crossings during the random platform test. For the trained site, data are the average number of platform crossings during the three trials that the platform was located in the other sites. For the other sites, data are the average number of platform crossings for all three of the other sites during the three trials that the platform was located in the trained site.* Significant difference $(P<0.005)$ between the trained site and other site data. Data are represented as the mean ( \pm S.E.M.).
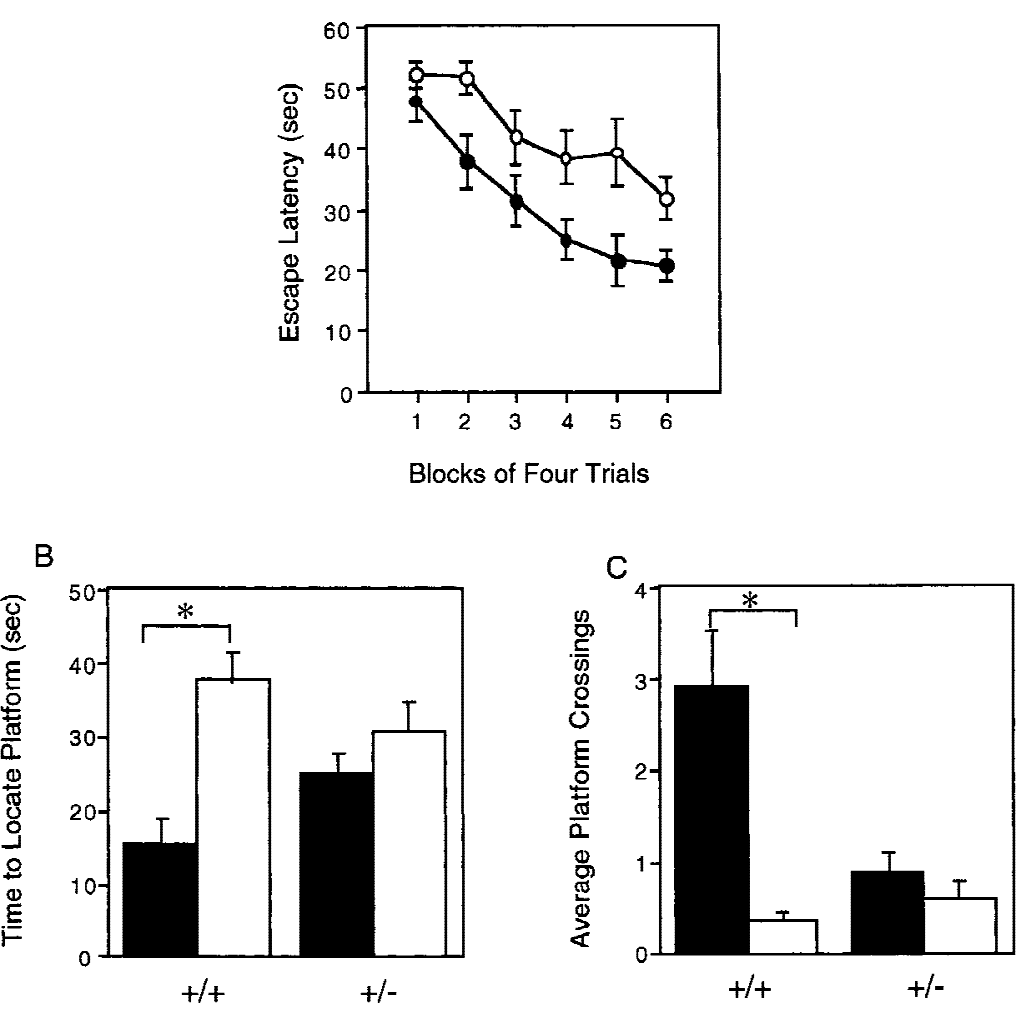

Trained $\square$ Other
(Dobyns et al. 1993) result from hemizygous deletions of $17 \mathrm{p} 13.3$. The smooth brain appearance, or lissencephaly, is thought to be a consequence of abnormal neuronal migration. All humans with ILS or MDS have profound mental retardation, and most have seizures. Lis 1 was identified as the gene responsible for type 1 lissencephaly (Reiner et al. 1993). To study the in vivo function of Lis 1 we disrupted Lis 1 in mice. The brain abnormalities displayed by heterozygous Lis 1 mutant mice are strikingly similar to those of ILS and MDS patients. The present findings indicate that neuronal migration defects produced by a Lis 1 mutation has a detrimental impact on selective central nervous system functions resulting in impairments in certain complex behavioral response.

\section{IMPAIRED SPATIAL LEARNING IN Lis1HET MUTANT MICE}

Spatial learning performance was impaired in Lis1HET mice. In experiment 1, Lis1HET mice did not search selectively in the correct quadrant of the pool during the probe trials after hidden platform training in the Morris water task. However, during these probe trials, wild-type mice spent more time in the correct quadrant of the pool compared to the other quadrants, and crossed the exact site where the platform had been located more often compared to comparable sites in the other quadrants. The probe trial results may appear to contrast those data obtained during training because Lis1HET and wild-type mice had similar escape latencies during training. However, it is important to remember that the escape latency data by itself are not compelling and do not indicate the type of search strategy being used; data from some type of test trial is necessary to determine whether a group of mice is using a spatially biased search strategy. Recent reports have found that mouse performance during training often does not predict what type of search performance will be elicited during a probe trial (Owen et al. 1997; Wolfer et al. 1998). In addition, other researchers have observed mutant mice that do not have an impairment during training, and do not show a selective

$$
\begin{array}{lllllllllllllll}
L & E & A & R & N & I & N & G & \underset{\mathbf{5 3 2}}{\mathbf{Z}} & M & E & M & O & R & Y
\end{array}
$$


spatial search strategy during the probe trial (e.g., Teacott et al. 1999).

In experiment 1 , the total number of platform crossings was similar between wild-type and Lis1HET mice; however, only wild-type mice crossed the training site significantly more often than all of the other sites. Lis1HET mice displayed some bias toward the correct area of the pool, but the number of platform crossings in the training quadrant was not statistically higher than the number of platform crossings in the other quadrants. Therefore, only the wild-type mice displayed a spatially biased search strategy that was statistically significant. The fact that the total number of platform crossings was similar between wild-type and Lis1HET mice suggests that both groups of mice swim away from the wall and search the correct distance away from the wall where the platform could have been located. If the Lis1HET mutants were impaired because they were thigmotaxic and swimming along the edges of the walls (i.e., see Paylor and Rudy 1990) then they would have not crossed the same number of platform sites. Therefore, despite the similarity in performance during training, the probe data clearly demonstrate that wild-type mice, but not Lis1HET mice, learned the location of the hidden platform using a selective, spatial search strategy. It is important to note that experiment 2 was designed to further test the hypothesis that Lis1HET mutant mice have a spatial learning impairment in the Morris water task. In experiment 2, spatial learning performance was assessed using a random platform test. During the random platform test the platform is sometimes located in the same site as that used during training but on other trials it is randomly located in one of the other three quadrants. If an animal learned to locate the platform during training by using a spatially biased search strategy, then it will locate more rapidly the platform during the random platform trials when the platform is in the training site compared to when it is in one of the other three sites. However, if a subject learned to find the hidden platform during training using a search strategy that was not spatially biased it will take an equivalent amount of time to locate the platform during the random platform test independent of the actual platform location. The findings from the random platform test confirm the hypothesis that wild-type mice, but not Lis1HET mutants, learn the location of a hidden platform using a spatially biased search strategy. In experiment 2, wild-type mice found the platform significantly faster during the random platform test when the platform was in the same location as that used during training compared to when the platform was located in one of the other quadrants. Lis1HET mutant mice, however, took an equivalent amount of time to locate the hidden platform during the random platform test when the platform was in the original training site as when it was in one of the other three quadrants.

In contrast to experiment 1 , the Lis1HET mutants mice in experiment 2 took significantly longer to locate the hidden platform during training compared to wild-type mice. Although it is not clear why these two findings are different as there were several differences between the experiments including testing site, shipping mice, training history, it is clear that the Lis1HET mutant mice have a spatial learning impairment.

The disorganized hippocampal region and impaired spatial learning in the Lis1HET mice are consistent with the impaired spatial learning performance of mice and rats with hippocampal damage (Morris et al. 1982; Sutherland et al. 1982; Logue et al. 1997). Although there is debate about the exact role of the hippocampus in learning and memory, most researchers agree that damage to the hippocampal formation produces selective learning and memory impairments. In addition to impaired spatial learning, animals with hippocampal formation dysfunction are impaired on a number of other learning tests including contextual fear conditioning test, conditional alternation in a T-maze, negative and transverse patterning, and avoidance responding (Aggleton et al. 1986; Green and Stanton 1989; Rudy and Sutherland 1989; Kim and Faneslow 1992; Phillips and LeDoux 1992; Alvarado and Rudy 1995; Logue et al. 1997). However, there are a number of tasks that can be solved by animals with hippocampal damage such as the visible platform version of the Morris task, auditory cue conditioned fear, position learning, and simultaneous visual discriminations (Morris et al. 1982; Kim and Faneslow 1992; Logue et al. 1997). These performance dissociations are the hallmark for identifying mutant mice with possible hippocampal dysfunction. To better understand the role of neuronal migration defects that result in the disorganized hippocampus seen in Lis1HET mice, future studies will evaluate the performance of Lis1HET mice on each of these tests. In addition, studies are in progress to characterize the synaptic properties of hippocampal slices from Lis1HET mice.

$$
\begin{array}{lllllllllllllll}
\hline & E & A & R & N & I & N & G & \underset{\mathbf{5} 33}{\mathbf{Z}} & M & E & M & O & R & Y
\end{array}
$$


Paylor et al.

Neuronal migration defects are present in other brain regions including the cortex, cerebellum, and olfactory bulb of Lis1HET mutant mice (Hirotsune et al. 1998). Because damage to brain regions other than the hippocampus, including several cortical areas, can lead to spatial learning impairments in the Morris water task (e.g., Sutherland et al. 1982), future studies using mutant mice with region-specific conditional mutations of the Lis1 gene will be necessary to clearly determine which brain abnormalities contribute to the spatial learning impairment.

\section{IMPAIRED MOTOR BEHAVIOR IN LiS1HET MUTANT MICE}

Lis1HET mutant mice were also unable to walk on top of the rotating rod as long as wild-type control mice. The rotarod impairment was observed in both experiments 1 and 2 . The impairment appears to be present during the first trial, which suggests that baseline motor coordination is impaired in the Lis1HET mutants. In addition, the data from experiment 2 indicate that the magnitude of the performance improvement from trial 1-9 is greater in wild-type than in Lis1HET mice. Specifically, the average increase in the time spent walking on the rotarod from trial 1-9 for Lis1HET mice was $48.8 \mathrm{sec}( \pm 14.1 \mathrm{sec})$. In contrast, the average increase in the time spent walking on the rotarod from trial 1 to trial 9 for wild-type mice was $126.4 \mathrm{sec}( \pm 12.8)$. These findings suggest that Lis1HET mutant mice have a motor coordination and skill learning impairment as assessed by the accelerating rotarod test.

As described in the Methods section, mice can be divided into two groups based on their behavior on the rotarod as they begin to loose their balance. We have operationally defined those mice that ride around the rod at least one time during training as passive-performing mice, whereas those that never passively ride around the rotarod are referred to as active-performing mice. In the present study, a similar percentage of wild-type and Lis1HET mutants were characterized as passive-performing mice (wild-type, 61\%; Lis1HET, 65\%) and activeperforming mice (wild-type, 39\%; Lis1HET, 35\%). The data from experiment 2 clearly demonstrate that Lis1HET mutants are impaired at the rotarod regardless of being classified as an active- or passive-performing mouse. However, it is interesting to note that Lis1HET mutants classified as active- performing show very little improvement over the nine training trials. The average increase in time spent on the rotarod from trial 1 to 9 for activeperforming Lis1HET mice was 18.4 seconds $( \pm 9.9$ sec) compared to $101 \mathrm{sec}( \pm 8.4 \mathrm{sec})$ for activeperforming wild-type mice. Thus, the only improvement in performance on the rotarod for Lis1HET mutants is for those that were classified as passive-performing mice.

In experiment 1 we document that a significant number of Lis1HET mice clutched their hindpaws to their bodies when suspended by their forepaws or their tail. This hind-limb clutching response was never observed in the wild-type mice. In addition, there was a trend toward lower locomotor activity and rearing behavior in the open field in the Lis1HET mice; however, these differences were not significant. These findings suggest that the Lis1 mutation affects neuronal processes that contribute to certain types of motor behaviors and skill learning. Although there are no major neuronal abnormalities in the cerebellum or spinal cord of the Lis 1 mutant mice, in vitro assays using cultured cerebellum show that there are differences in migration of granule cells between wildtype and Lis 1 mutant mice (Hirotsune et al. 1998). In addition, compound heterozygous mice have severe defects in cerebellar neuronal migration (Hirotsune et al. 1998). Thus, there are likely to be subtle differences in cerebellar neurons between wild-type and Lis1HET mice that could lead to functional impairments in motor behaviors. The execution of motor responses involves a range of neural systems including cortical regions. Therefore, it is possible that the disorganized cortex may be contributing to the motor impairment observed in the Lis 1 mutant mice. Further anatomical and electrophysiological studies will be necessary to better understand the neurological basis for the motor impairments observed in Lis 1 heterozygous mutant mice.

Correlational analyses between motor performance and spatial learning were performed because it is possible that the motor defects in Lis1HET mutants could have contributed to the spatial learning impairments. However, there was no significant relationship between the motor impairment and performance on the Morris water task. These findings support the hypothesis that the motor and spatial learning impairments displayed by Lis1HET are independent, and reflect two distinct central nervous system abnormalities.

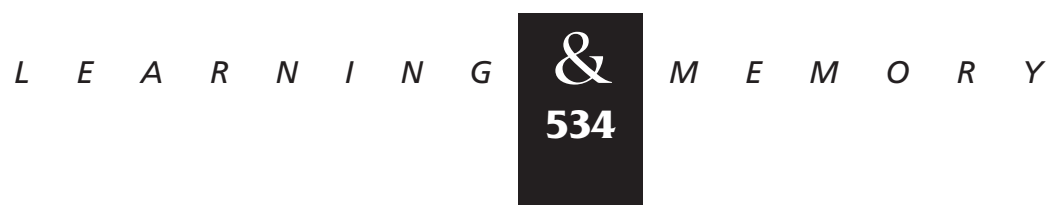


RELIABILITY OF BEHAVIORAL PHENOTYPES IN Lis1HET MUTANT MICE

Recently a paper by Crabbe et al. (1999) demonstrated that there are significant differences in the behavioral responses of inbred and mutant mice that depend on the actual testing site. These researchers suggest that the significant differences in behavior illustrate the influence of uncontrolled environmental factors on the behavioral responses of mice. Furthermore they recommend that all significant phenotypes with mutant mice should be replicated, and if possible at a second laboratory site. In the current study, the motor and spatial learning impairments were found both at a laboratory at NIMH (Bethesda, MD) and at BCM (Houston, TX). Therefore, the behavioral impairments of Lis1HET mutant mice appear to be quite robust and reliable. However, there were differences between the data obtained at NIMH and at BCM. First, Lis1HET mutant mice were not impaired at locating the hidden platform compared to wild-type mice in the experiment performed at NIMH, but they were significantly impaired when tested at BCM. Second, comparing the data from the rotarod test in experiment 1 performed at NIMH, and the first day of training in experiment 2 performed at BCM it is clear that both Lis1HET mutants and wildtype mice performed more poorly at BCM. The exact nature of these differences in the data sets is not known because there were a number of environmental differences between NIMH and BCM. However, the differences are not simply due to differences in the testing equipment, as the size of the pool and escape platforms used for the Morris experiments were identical, and the same UGOBasile accelerating rotarod was used at both sites. In addition, the exact genetic makeup of the mice is likely to be different as the mice were not on a pure inbred background. Despite all these differences the Lis1HET mutants displayed consistent motor behavior and spatial learning impairments in both laboratories.

\section{NEURONAL MIGRATION DEFECTS AND BEHAVIOR}

It may be somewhat surprising that the Lis 1 mutation did not produce more severe behavioral abnormalities such as that seen in reeler mutant mice. Reeler mice have a very demonstrative motor impairment resulting from neuronal migration defects (Falconer 1951; Rakic and Caviness 1995). However, the neuronal abnormalities observed in reeler mice are distinct from those observed in Lis 1 mutant mice. For example, reeler mice display cortical layer inversion (Caviness 1982), and no defects have been observed in cerebellar migration assays (Nagata and Terashima 1994). In contrast, there are no cortical inversions in Lis 1 mutant mice, and mutant neurons display cell autonomous migration defects in a cerebellar reaggregate migration assay (Hirotsune et al. 1998). Thus, the differences in the neuronal abnormalities between reeler and Lis 1 mutant mice may result in distinct behavioral phenotypes.

Although the behavioral abnormalities in Lis1 mutant mice may not be obvious without evaluating mice using assays that are sensitive to central nervous system dysfunction, they are consistent with a number of animal model systems used to study the functional impact of neuronal migration defects on behavior. For example, treating gestating rats with methylazoxymethanol (MAM) results in alterations of neuronal circuitry in various brain regions of the offspring (e.g., Di Luca and Cattabeni 1991). MAM is a potent antimitotic agent that can produce hypoplasia in brain regions where cells are still rapidly dividing during the treatment period. Although MAM treatment at E15 results in up to $50 \%$ reduction of cortical and hippocampal regions (Di Luca and Cattabeni 1991; Moran and Coyle 1991), the behavior of animals exposed to MAM is relatively unimpaired (e.g., Ferguson et al. 1993). However, MAM-treated microcephalic animals do have learning and memory impairments on test assay spatial learning such as the radial maze (for review, see Berger-Sweeney and Hohmann 1997). Therefore, certain types of neuronal migration defects like that observed in reeler mice can have dramatic effects on behavior, whereas neuronal abnormalities associated with the Lis 1 mutation or MAM treatment lead to more subtle, specific behavioral impairments.

However, there are secondary consequences of neuronal migration defects in humans not displayed in mice. During normal brain development in humans, the cortex becomes folded, increasing the cortical surface area. A secondary consequence of the migration defect in individuals with type I lissencephaly is the development of a brain with a smooth cortical surface. The neuronal migration defects in the Lis1 mutant mice do not result in such effects on the development of the cortical surface because migration in the normal mouse terminates before cortical folding. Therefore, it is not surprising that individuals with type I lissen-

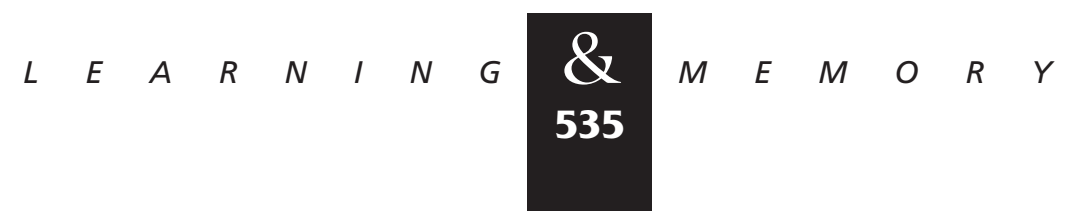


cephaly have severe mental retardation and that Lis 1 mutant mice have a modest learning and memory impairment, as there are secondary consequences of migration defects that are species specific. It is also important to keep in mind that it is difficult to know how to equate spatial learning performance of mice, or for that matter learning performance on any task, to the types of learning impairments observed in individuals with mental retardation.

\section{CONCLUSIONS}

The primary neuronal migration defect appears to be the same in individuals with type 1 lissencephaly and the Lis 1 mutant mice. Thus, the Lis1HET mutants provide a model for the primary neuronal migration defects observed in human type 1 lissencephaly. Developmental analysis of the onset of the patterning defects in the brain of Lis 1 mutant mice (Hirotsune et al. 1998) demonstrate that they appear to be the result of slow or delayed neuronal migration with an onset near E17.5. These developmental impairments in neuronal migration are likely the cause of the motor and spatial learning impairments observed in adult Lis1HET mice. We believe that Lis1HET mutants can be a useful tool for understanding the molecular basis for neural migration defects and the functional role of neuronal migration defects in central nervous system function.

\section{Acknowledgments}

We thank Lisa Garrett and Theresa Hernandez for excellent technical assistance. This Work was supported in part by the Baylor Mental Retardation Research Center (P30 HD24064-11).

The publication costs of this article were defrayed in part by payment of page charges. This article must therefore be hereby marked "advertisement" in accordance with 18 USC section 1734 solely to indicate this fact.

\section{References}

Abeliovich, A., R. Paylor, C. Chen, J.J. Kim, J.M. Wehner, and S. Tonegawa. 1993. PKC $\gamma$ mutant mice exhibit mild learning deficits in spatial and contextual learning. Cell 75: $1263-1271$.

Aggleton, J.P., P.R. Hunt, and J.N.P. Rawlins. 1986. The effects of hippocampal lesions upon spatial and nonspatial tests of working memory. Behav. Brain Res. 19: 133-146.

Albrecht, U., R. Abu-Issa, B. Ratz, M. Hattori, J. Aoki, H. Arai, K. Inoue, and K.G. Eichele. 1996. Platelet-activating factor acetylhydrolase expression and activity suggest a link between neuronal migration and platelet-activating factor. Dev. Biol. 180: 579-593.
Alvarado, M.C. and J.W. Ruby. 1995. Rats with damage to the hippocampal-formation are impaired on the transverse-patterning problem but not on elemental discriminations. Behav. Neurosci. 109: 204-211.

Berger-Sweeney, J. and C.F. Hohmann. 1997. Behavioral consequences of abnormal cortical development: Insights into developmental disabilities. Behav. Brain Res. 86: $121-142$.

Caine, S.B., M.A. Geyer, and N.R. Swerdlow. 1992. Hippocampal modulation of acoustic startle and prepulse inhibition in the rat. Pharm. Biochem. Behav. 43: 1201-1208.

Caviness, V.S. 1982. Neocortical histogenesis in normal and reeler mice: A developmental study based upon

[3H]thymidine autoradiography. Dev. Brain Res. 4: 293-302.

Crabbe, J.C., D. Wahlsten, and B.C. Dudek. 1999. Genetics of mouse behavior: Interactions with laboratory environment. Science 284: 1670-1672.

Crawley, J.N. and R. Paylor. 1997. A proposed test battery and constellations of specific behavioral paradigms to investigate the behavioral phenotypes of transgenic and knockout mice. Horm. Behav. 31: 197-211.

Di Luca, M. and F. Cattabeni. 1991. Transplacentally induced brain lesions: An animal model to study molecular correlates of cognitive deficits. Neurosci. Res. Comm. 9: $127-136$.

Dobyns, W.B., O. Reiner, R. Carrozzo, and D.H. Ledbetter. 1993. Lissencephaly. A human brain malformation associated with deletion of the LIS1 gene located at chromosome 17p13. JAMA 270: 2838-2842.

Falconer, D.S. 1951. Two new mutants "trembler" and "reeler" with neurological actions in the house mouse (Mus musculus). J. Genet. 50: 192-201.

Ferguson, S.A., F.D. Racey, M.G. Paule, and R.R. Holson. 1993. Behavioral effects of methylazoxymethanol-induced micrencephaly. Behav. Neurosci. 107: 1067-1076.

Green, R.J. and M.E. Stanton. 1989. Differential ontogeny of working memory and reference memory in the rat. Behav. Neurosci. 103: 98-105.

Hattori, M., H. Adachi, M. Tsujimoto, H. Arai, and K. Inoue. 1994. Miller-Dieker lissencephaly gene encodes a subunit of brain platelet-activating factor acetylhydrolase. Nature 370: 216-218.

Hirotsune, S., M.W. Fleck, G.J. Bix, M.J. Gambello, A. Chen, G.D. Clark, D.H. Ledbetter, C.J. McBain, and A.

Wynshaw-Boris. 1998. Graded reduction of PafaH1b1 (Lis1) activity in vivo results in neuronal cell autonomous migration defects and early embryonic lethality. Nat. Genet. (in press).

Kim, J.J. and M.S. Fanselow. 1992. Modality-specific retrograde amnesia of fear. Science 256: 675-677.

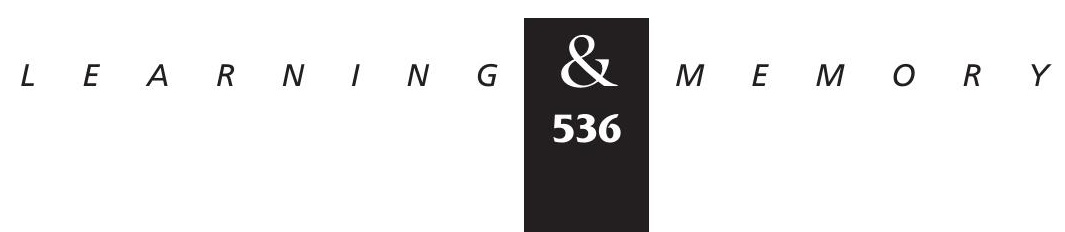


Lijam, N., R. Paylor, M.P. McDonald, J.N. Crawley, C. Deng, K. Herrup, K.E. Stevens, G. Maccaferri, C.J. McBain, D.J. Sussman, and A. Wynshaw-Boris. 1997. Social interaction and sensorimotor gating abnormalities in mice lacking Dv/1. Cell 90: 895-905.

Logue, S.F., R. Paylor, and J.M. Wehner. 1997. Hippocampal lesions cause learning deficits in inbred mice in the Morris water maze and conditioned-fear task. Behav. Neurosci. 111: 104-113.

Miller, C.L. and R. Freedman. 1995. The activity of hippocampal interneurons and pyramidal cells during the response of the hippocampus to repeated auditory stimuli. Neuroscience 69: 371-381.

Moran, T.H. and J.T. Coyle. 1991. Effects of fetal methylazoxymethanol acetate on neural and behavioral development. In Developmental psychobiology: New methods and changing concepts, pp. 303-320. (ed. H.N. Shair, G.A. Barr, and M.A. Hofer.) Oxford University Press, NY.

Morris, R.G.M. 1981. Spatial localization does not depend upon the presence of local cues. Learn. Motiv. 12: 239-260.

Morris, R.G.M., P. Garrud, J.N.P. Rawlins, and J. O'Keefe. 1982. Place navigation impaired in rats with hippocampal lesions. Nature 297: 681-683.

Nagata, I. and R. Terashima. 1994. Migration behavior of granule cells on laminin in cerebellar microexplant cultures from early postnatal reeler mutant mice. Int. J. Dev. Neurosci. 12: 387-395.

Owen, E.H., S.F. Logue, D.L. Rasmussen, and J.M. Wehner. 1997. Assessment of learning by the Morris water task and fear conditioning in inbred mouse strains and $F_{1}$ hybrids: Implications of genetic background for single gene and quantitative trait loci analyses. Neuroscience 80: 1087-1099.

Paylor, R. and J.N. Crawley. 1997. Inbred strain differences in prepulse inhibition of the mouse startle response. Psychopharmacology 132: 169-180.

Paylor, R. and J.W. Rudy. 1990. Cholinergic receptor blockade can impair the rat's performance on both the place learning and cued versions of the Morris water task: The role of age and pool wall brightness. Behav. Brain Res. 36: 79-90.

Paylor, R., L. Baskall-Baldini, L. Yuva, and J.M. Wehner. 1996. Developmental differences in place-learning performance between $\mathrm{C} 57 \mathrm{BL} / 6$ and $\mathrm{DBA} / 2$ mice parallel the ontogeny of hippocampal protein kinase C. Behav. Neurosci. 110: $1415-1425$.

Paylor, R., M. Nguyen, J.N. Crawley, J. Patrick, A. Beaudet, and A. Orr-Urtreger. 1998. $\alpha 7$ nicotinic receptor subunits are not necessary for hippocampal-dependent learning or sensorimotor gating: A behavioral characterization of Acra7-deficient mice. Learn. Mem. 5: 302-316.
Phillips, R.G. and J.E. LeDoux. 1992. Differential contribution of amygdala and hippocampus to cued and contextual fear conditioning. Behav. Neurosci. 106: 274-285.

Rakic, P. and V.S. Caviness. 1995. Cortical development: View from neurological mutants two decades later. Neuron 14: 1101-1104.

Reiner, O., R. Carrozzo, Y. Shen, M. Wehnert, F. Faustinella, W.B. Dobyns, C.T. Caskey, and D.H. Ledbetter. 1993. Isolation of a Miller-Dieker lissencephaly gene containing G protein beta-subunit-like repeats. Nature 364: 717-721.

Reiner, O., U. Albrecht, M. Gordon, K.A. Chianese, C. Wong, O. Gal-Gerber, T. Sapir L.D. Siracusa, A.M. Buchberg, C.T. Caskey, and G. Eichele. 1995. Lissencephaly gene (LIS1) expression in the CNS suggests a role in neuronal migration. J. Neurosci. 15: 3730-3738.

Rudy, J.W. and R.J. Sutherland. 1989. The hippocampus is necessary for rats to learn and remember configural discriminations. Behav. Brain Res. 34: 97-109.

Silva, A.J., R. Paylor, J.M. Wehner, and S. Tonegawa. 1992. Impaired spatial learning in a calcium-calmodulin kinase II mutant mice. Science 257: 206-211.

Sterneck, E., R. Paylor, V. Jackson-Lewis, M. Libbey, S. Przedborski, L. Tessarollo, J.N. Crawley, and P.F. Johnson. 1998. Selectively enhanced contextual fear conditioning in mice lacking the transciptional regulator CCAAT/enhancer binding protein $\delta$. Proc. Natl. Acad. Sci. 95: 10908-10913.

Stevens, K.E. and K.D. Wear. 1997. Normalizing effects of nicotine and a novel nicotinic agonist on hippocampal auditory gating in two animal models. Pharm. Biochem. Behav. 57: 869-874.

Sutherland, R.J., B. Kolb, and I.Q. Whishaw. 1982. Spatial mapping: Definitive disruption by hippocampal or medial frontal cortical damage in the rat. Neurosci. Lett. 31: 271-276.

Swerdlow, N.R., B.K Lipska, D.R. Weinberger, D.L. Braff, G.E. Jaskiw, and M.A. Geyer. 1995. Increased sensitivity to the sensorimotor gating-disruptive effects of apomorphine after lesions of medial prefrontal cortex or ventral hippocampus in adult rats. Psychopharmacology 122: 27-34.

Tecott, L.H., S.F. Logue, J.M. Wehner, and J.A. Kauer. 1998. Pertubated dentate gyrus function in serotonin 5-HT2C receptor mutant mice. Proc. Natl. Acad. Sci. 95: 15026-15031.

Upchurch, M. and J.M. Wehner. 1988. Differences between inbred strains of mice in Morris water maze performance. Behav. Genet. 18: 55-68.

Wolfer, D.P., M. Staglijar-Bozicevic, M.L. Errington, and H.-P. Lipp. 1998. Spatial memory and learning in transgenic mice: Fact or artifact? News in Physiol. Sci. 13: 118-123.

Received July 19, 1999; accepted in revised form August 9, 1999.

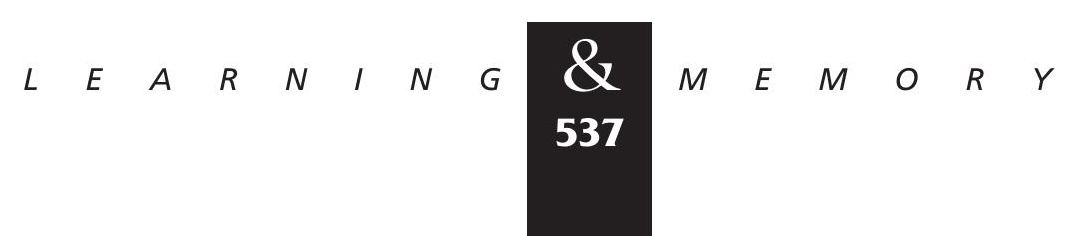




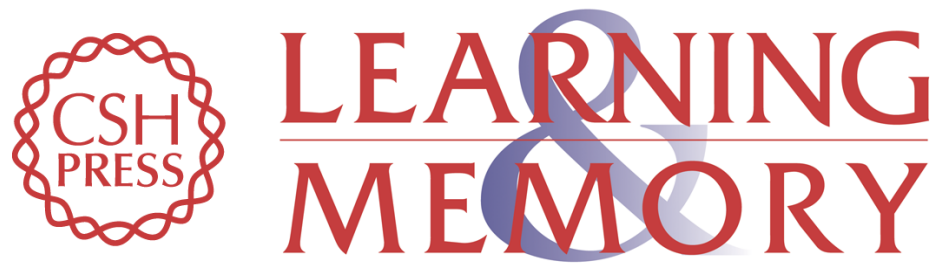

\section{Impaired Learning and Motor Behavior in Heterozygous Pafah1b1 (Lis1) Mutant Mice}

Richard Paylor, Shinji Hirotsune, Michael J. Gambello, et al.

Learn. Mem. 1999, 6:

Access the most recent version at doi:10.1101//m.6.5.521

References This article cites 40 articles, 7 of which can be accessed free at:

http://learnmem.cshlp.org/content/6/5/521.full.html\#ref-list-1

License

Email Alerting Receive free email alerts when new articles cite this article - sign up in the box at the Service top right corner of the article or click here. 